\title{
HUBUNGAN SELF EFFICACY DENGAN TINGKAT KEPATUHAN PENGOBATAN HIPERTENSI DI PUSKESMAS BARENG KOTA MALANG
}

\author{
Ellia Ariesti, Yafet Pradikatama P \\ Prodi DIII Keperawatan, Akademi Keperawatan Panti Waluya Malang \\ Email : ellianathanael@gmail.com
}

\begin{abstract}
Abstrak
Hipertensi adalah faktor risiko pada terjadinya penyakit kardiovaskular dan cerebrovascular. Identifikasi tingkat kepatuhan pasien dalam menggunakan obat terutama pada pasien rawat jalan perlu dilakukan, mengingat pasien menggunakan obat sendiri tanpa ada pengawasan dari tenaga kesehatan. Guna mencapai pengobatan yang efektif dan menunjang kepatuhan dalam minum obat, perawat perlu terlibat dalam program penyampaian informasi mengenai pengobatan hipertensi melalui metode self efficacy. Metode penelitian menggunakan penelitian korelasional dengan desain penelitian cross sectional untuk melihat bagaimana hubungan antara selfefficacy dengan tingkat kepatuhan pengobatan pada penderita hipertensi di Puskesmas Bareng Kota Malang. Populasi dalam penelitian ini adalah penderita hipertensi yang telah melakukan pengobatan, Penentuan sampel dilakukan dengan teknik purposive sampling. Uji statistik yang digunakan adalah Rank Spearmen Test. Hasil Penelitian didapatkan nilai signifikan Sig. (2-tailed) adalah $0.155(>0,05)$ sehingga disimpulkan bahwa H0 gagal ditolak yaitu tidak ada hubungan antara self efficacy dengan kepatuhan pengobatan hipertensi lansia. Tidak terdapatnya hubungan pada penelitian ini disebabkan karena walaupun sebagian output besar responden memiliki self efficacy sedang, namun kepatuhan berobatnya rendah, dan juga yang memiliki self efficacy tinggi sebagian besar juga memiliki kepatuhan berobat yang rendah; lama menderita hipertensi dibawah 5 tahun dan semua responden tidak ada komplikasi dari penyakit hipertensi walaupun sebagian besar sudah mendapat informasi dari tenaga kesehatan, dukungan keluarga bahkan memiliki asurasi kesehatan
\end{abstract}

Kata Kunci: Self efficacy, Kepatuhan, Pengobatan Hipertensi

\begin{abstract}
Hypertension is a risk factor for the occurrence of cardiovascular and cerebrovascular diseases. Identification of level of patient compliance in using drugs, especially in outpatients, needs to be done, given that patients use their own medication without supervision from health workers. In order to achieve effective treatment, nurses need to be involved in the program of delivering information about the treatment of hypertension through selfefficacy methods to support adherence in taking medication. The research method uses correlational research with a cross sectional research design that aims to see how the relationship between self-efficacy and the level of medication adherence in patients with hypertension in Bareng Health Center. The populations in this study were hypertensive patients who had been treated. The sample was determined using purposive sampling technique. The statistical test used Rank Spearmen Correlation test. The results of the study obtained significant values Sig. (2-tailed) is 0.155, where this result is >0.05, so it can be concluded that HO failed to be rejected, namely there is no relationship between self-efficacy and adherence to elderly hypertension treatment. The absence of a relationship in this study was due to the fact that although most of the large outputs of respondents had moderate self-efficacy, the adherence to treatment was low, and also those who had high self-efficacy also had low treatment compliance; length of hypertension is still under 5 years and all respondents had no complications from hypertension even though most of them had received information from health workers, family support even had health insurance
\end{abstract}

Keywords: Self efficacy, Compliance, Hypertension Treatment

\section{PENDAHULUAN}

Hipertensi adalah faktor risiko terjadinya penyakit kardiovaskular dan cerebrovascular. Kerusakan organ tubuh yang penting seperti jantung, otak, ginjal dan pembuluh darah dapat terjadi akibat tingginya tekanan darah. Risiko relatif terjadinya stroke dan penyakit jantung koroner meningkat sesuai dengan meningkatkan 
tekanan diastolik dan tekanan sistolik (Prodjosudjadi, 2000).

Menurut WHO tekanan darah yang tidak optimal (tekanan darah sistolik >115 mmHg) dapat menyebabkan 7,1 juta kematian per tahun di seluruh belahan dunia (Lawes, 2004). Kejadian hipertensi diperkirakan terus meningkat, terutama di negara berkembang, dari sejumlah 639 juta kasus di tahun 2000 menjadi 1,15 miliar kasus di tahun 2025. Prediksi ini didasarkan pada angka penderita hipertensi saat ini dan pertambahan penduduk saat ini (Armilawaty, 2007).

Di Indonesia masalah hipertensi cenderung meningkat. Hasil riset kesehatan dasar (Riskesdas) tahun 2013 menyebutkan bahwa terjadi peningkatan prevalensi hipertensi dari 7,6\% pada tahun 2007 menjadi 9,5\% pada tahun 2013 (Riskesdas, 2013).

Hipertensi sangat erat hubungannya dengan faktor gaya hidup dan pola makan. Gaya hidup sangat berpengaruh pada bentuk perilaku atau kebiasaan seseorang yang mempunyai pengaruh positif maupun negatif pada kesehatan. Hipertensi belum banyak diketahui sebagai penyakit yang berbahaya, padahal hipertensi termasuk penyakit "silent killer". Kejadian hipertensi ditemukan ketika dilakukan pemeriksaan rutin/saat pasien datang dengan keluhan lain. Hipertensi pada dasarnya mengurangi harapan hidup para penderitanya.

Salah satu tugas perawat adalah memberikan pendidikan kesehatan agar penderita hipertensi mengerti mengenai program pengobatannya. Selain itu, perawat juga berkolaborasi dengan Dokter atau pharmaceutical care untuk mengidentifikasi drug related problem pada pasien dengan tujuan menjalankan dan memonitor rancangan terapi pasien hipertensi mengenai drug related problem. Salah satu aspek pada drug related problem adalah masalah yang berkaitan dengan tingkat kepatuhan terhadap pengobatan (Cipolle dkk., 1998).

Guna mencapai pengobaatan yang efektif, perawat perlu terlibat dalam program penyampaian informasi mengenai pengobatan hipertensi melalui metode self efficacy guna menunjang kepatuhan dalam minum obat. Berdasarkan Sarafino \& Smith (2011) hal yang paling terpenting yang harus dimiliki oleh individu untuk dapat melaksanakan perilaku sehat adalah self-efficacy.

Berdasarkan data dari website Puskesmas Bareng, didapatkan data pada tahun 2016 hipertensi merupakan salah satu 10 penyakit terbanyak, dan hipertensi berada pada urutan pertama dengan jumlah posentase 19, $30 \%$ dari total 10 penyakit terbanyak tahun 2016. Pada tahun 2017, selama 3 bulan terakhir yaitu bulan Juni - Agustus 2017, hipertensi juga merupakan 10 penyakit terbanyak di Puskesmas Bareng. Jumlah rata-rata penderita hipertensi selama bulan Juni - Agustus 2017 adalah 273 penderita baik itu penderita baru maupun lama (Puskesmas Bareng, 2017).

Melihat fenomena penyakit hipertensi sebagai 10 penyakit terbanyak di Puskesmas Bareng, maka peneliti tertarik untuk melakukan penenelitian tentang hubungan antara SelfEfficacy dengan tingkat kepatuhan pengobatan pada penderita Hipertensi di Puskesmas Bareng 
Kota Malang. Sehingga dengan adanya penelitian ini diharapkan dapat memberikan kontribusi pada tercapainya kepatuhan pengobatan penderita hipertensi sehingga juga akan menurunkan jumlah drop out pengobatan penderita hipertensi.

\section{METODE PENELITIAN}

Jenis penelitian yang digunakan dalam penelitian ini adalah penelitian korelasional. Metode korelasional meneliti hubungan atau pengaruh sebab akibat. Metode ini digunakan untuk meneliti bagaimana hubungan antara selfefficacy dengan tingkat kepatuhan pengobatan pada penderita hipertensi di Puskesmas Bareng Kota Malang. Penelitian ini bertujuan untuk menganalisis hubungan antara variabel yang ada.

\section{Populasi dan sampel penelitian}

Populasi dalam penelitian ini adalah penderita hipertensi yang telah melakukan pengobatan di Puskesmas Bareng Kota Malang. Penentuan sampel dilakukan dengan menggunakan teknik purposive sampling, Jumlah sampel dalam penelitian ini sebanyak 100 reponden.

\section{Lokasi dan Waktu Penelitian}

Penelitian dilakukan di Puskesmas Bareng Kota Malang dan Seluruh proses penelitian dilakukan sampai dengan terpenuhinya jumlah sampel selama 5 bulan yaitu mulai bulan Oktober 2017 s/d bulan Februari 2018.

\section{Prosedur Penelitian}

Prosedur penelitian yang dilaksanakan dalam penelitian ini adalah dengan cara responden dipilih dengan menggunakan tehnik Purposive sampling. Selanjutnya dilakukan pengukuran terhadap dua variabel, setelah itu dilakukan tabulasi dan pengolahan data.

\section{Pengumpulan Data}

Data akan dikumpulkan secara langsung dari responden dengan menggunakan lembar kuesioner general self efficacy scale 12 sebagai alat untuk mengukur self efficacy pasien dan lembar kuesioner kepatuhan pengobatan dengan metode MMAS (modified morisky adherence scale) untuk mengukur kepatuhan kontrol dan konsumsi obat hipertensi.

\section{Analisis Data}

Program pengolahan data menggunakan SPSS 16. Analisis data yang digunakan untuk menguji hubungan antara depresi pada lansia dengan Kemandirian lansia di posyandu lansia dilakukan dengan adalah uji uji statistik Korelasi Rank Spearman menggunakan aplikasi SPSS 16 for Windows dengan nilai nilai signifikansi atau Sig. (2-tailed) adalah 0,155, dimana hasil ini $>0,05$, sehingga dapat didimpulkan bahwa H0 gagal ditolak yaitu tidak ada hubungan antara self efficacy dengan kepatuhan pengobatan hipertensi lansia di Puskesmas Bareng Kota Malang. 


\section{HASIL PENELITIAN}

\section{Data Umum}

Penelitian ini mengambil subyek penelitian yang terdiri dari 100 lansia dengan karakteristik umum subyek penelitian dapat dilihat pada tabel 1 .

Tabel 1 Distribusi frekuensi karakteristik responden penderita hipertensi di Puskesmas Bareng Malang.

\begin{tabular}{|c|c|c|}
\hline Kategori & Frekuensi & $(\%)$ \\
\hline \multicolumn{3}{|c|}{ Lama Menderita } \\
\hline$<5$ tahun & 81 & 81 \\
\hline$\geq 5$ Tahun & 19 & 19 \\
\hline \multicolumn{3}{|l|}{ Komplikasi } \\
\hline Ada & 0 & 0 \\
\hline Tidak Ada & 100 & 100 \\
\hline \multicolumn{3}{|l|}{ Informasi } \\
\hline Pernah & 60 & 60 \\
\hline Tidak Pernah & 40 & 40 \\
\hline \multicolumn{3}{|l|}{ Dukungan } \\
\hline Keluarga & 90 & 90 \\
\hline Iya & 10 & 10 \\
\hline \multicolumn{3}{|l|}{ Tidak } \\
\hline \multicolumn{3}{|l|}{ Asuransi } \\
\hline Iya & 87 & 87 \\
\hline Tidak & 13 & 13 \\
\hline \multicolumn{3}{|c|}{ Dukungan Nakes } \\
\hline Iya & 95 & 95 \\
\hline Tidak & 5 & 5 \\
\hline \multicolumn{3}{|c|}{ Jarak rumah ke RS } \\
\hline $1-5 \mathrm{KM}$ & 98 & 98 \\
\hline 6-10 KM & 2 & 2 \\
\hline Jumlah & 100 & $100 \%$ \\
\hline
\end{tabular}

Berdasarkan tabel 1 distribusi frekuensi karakteristik responden, lama menderita hipertensi terbanyak $<5$ tahun sebanyak $81 \%$, tidak ada yang mengalami komplikasi hipertensi, $60 \%$ pernah mendapatkan informasi sebelumnya, $90 \%$ mendapatkan dukungan keluarga, 87\% mempunyai asuransi kesehatan, 95\% mendapatkan dukungan dari tenaga kesehatan dan $98 \%$ jarak rumah ke RS berjarak 1-5 KM.
Tabel 2 Distribusi Frekuensi self efficacy pada penderita hipertensi di Puskesmas Bareng.

\begin{tabular}{lll}
\hline Kategori & Frekuensi & $(\%)$ \\
\hline Rendah & 0 & $0 \%$ \\
Sedang & 73 & $73 \%$ \\
Tinggi & 27 & $27 \%$ \\
\hline Jumlah & 100 & $100 \%$ \\
\hline & Sumber : Data Primer Penelitian 2017
\end{tabular}

Berdasarkan tabel 2 distribusi frekuensi self efficacy, dominan pada kategori sedang, yaitu sebanyak 73 orang dengan presentase $73 \%$.

Tabel 3 Disribusi frekuensi kepatuhan kontrol penderita hipertensi di Puskesmas Bareng.

\begin{tabular}{lll}
\hline Kategori & Frekuensi & $(\%)$ \\
\hline Rendah & 76 & $76 \%$ \\
Sedang & 21 & $21 \%$ \\
Tinggi & 3 & $3 \%$ \\
\hline Jumlah & 100 & $100 \%$ \\
\hline \multicolumn{3}{c}{ Sumber : Data Primer Penelitian 2017 }
\end{tabular}

Berdasarkan tabel 3 distribusi frekuensi kepatuhan penderita hipertensi kontrol ke Puskesmas Bareng, dominan pada kategori rendah, yaitu sebanyak 76 orang dengan presentase $76 \%$.

\section{Data Khusus Penelitian}

Tingkat kepatuhan minum obat pada penderita hipertensi diukur menggunakan kuesioner MMAS (modified morisky adherence scale) dikategorikan menjadi tiga, yaitu tinggi, sedang dan rendah. Hasil pengukuran self eficacy pada penelitian ini didapatkan hasil sebagai berikut pada tabel 4 . 
Ellia Ariesti, Yafet Pradikatama P, Hubungan Self Efficacy...

Tabel 4 Distribusi frekuensi responden berdasarkan tingkat kepatuhan kontrol dan minum obat

\begin{tabular}{lllll}
\hline & & \multicolumn{2}{l}{ Self Eficacy } & \\
\cline { 3 - 4 } & & Sedang & Tinggi & Total \\
\hline \multirow{3}{*}{ Kepatu } & Tinggi & 1 & 2 & 3 \\
han & & $33,3 \%$ & $66,7 \%$ & $100 \%$ \\
& Sedang & 14 & 7 & 21 \\
& & $66,7 \%$ & $33,3 \%$ & $100 \%$ \\
& Rendah & 58 & 18 & 76 \\
\hline Total & $76,3 \%$ & $23,7 \%$ & $100 \%$ \\
& & 73 & 27 & 100 \\
& & $73 \%$ & $27 \%$ & $10 \%$ \\
\hline
\end{tabular}

Sumber : Data Primer Penelitian 2017

Tabel 4 menunjukkan terdapat 3 orang memiliki kepatuhan berobat tinggi dengan self efficacy sedang 1 responden dan tinggi 2 responden, 21 responden memiliki kepatuhan berobat sedang dengan self efficacy sedang 14 responden dan self efficacy tinggi 7 responden., dan yang terbanyak 76 responden memiliki kepatuhan berobat yang rendah dengan self efficacy 58 responden dan self efficacy tinggi 18 responden.

Tabel 5 Spearman Rank test

\begin{tabular}{|c|c|c|c|c|}
\hline & & & $\begin{array}{l}\text { Self } \\
\text { Eficacy }\end{array}$ & Kepatuhan \\
\hline \multirow{7}{*}{$\begin{array}{l}\text { Spear } \\
\text { man's } \\
\text { rho }\end{array}$} & \multirow{3}{*}{$\begin{array}{l}\text { Self } \\
\text { Eficacy }\end{array}$} & Corellation & 1.000 & -.143 \\
\hline & & $\begin{array}{l}\text { coefficient } \\
\text { Sig. (2-tailed) }\end{array}$ & & .155 \\
\hline & & $\mathrm{N}$ & 100 & 100 \\
\hline & \multirow{4}{*}{$\begin{array}{l}\text { Kepatu } \\
\text { han }\end{array}$} & Correlation & -.143 & 1000 \\
\hline & & Coefficient & & \\
\hline & & Sig. (2-tailed) & .155 & \\
\hline & & $\mathrm{N}$ & 100 & 100 \\
\hline
\end{tabular}

Sumber : Data Primer Penelitian 2017

Berdasarkan Tabel 5 menunjukkan nilai signifikan Sig. (2-tailed) adalah 0,155, dimana hasil ini > 0,05, sehingga dapat didimpulkan bahwa H0 gagal ditolak yaitu tidak ada hubungan antara self efficacy dengan kepatuhan pengobatan hipertensi lansia di Puskesmas Bareng Kota Malang.

\section{PEMBAHASAN}

Tidak terdapatnya hubungan pada penelitian ini disebabkan karena walaupun sebagian output besar responden memiliki self efficacy sedang, namun kepatuhan berobatnya rendah, dan juga yang memiliki self efficacy tinggi sebagian besar juga memiliki kepatuhan berobat yang rendah. Dari data umum responden, hal ini bisa disebabkan karena lama menderita hipertensi masih dibawah 5 tahun, dan semua responden tidak ada komplikasi dari penyakit hipertensi walaupun sebagian besar sudah mendapat informasi dari tenaga kesehatan, dukungan keluarga bahkan memiliki asurasi kesehatan (Armilawaty, 2007).

Berdasarkan beberapa teori yang mengatakan bahwa ketidakpatuhan dapat dikaitkan dengan kepercayaan pasien tentang penyakitnya dan kebutuhan akan pengobatan kaitannya dengan efek samping yang potensial sementara self efficacy dilihat dari dimensi social persuasion bahwa Informasi tentang kemampuan yang disampaikan secara verbal oleh seseorang yang berpengaruh biasanya digunakan untuk menyakinkan seseorang, dan dari dimensi mastery experience bahwa keberhasilan yang didapatkan akan meningkatkan efikasi diri yang dimilki seseorang sedangkan kegagalan akan menurunkan efikasi dirinya (Prodjosudjadi,2000). 


\section{KESIMPULAN}

Dari hasil penelitian dapat disimpulkan, sebanyak 73 responden (73\%) memiliki self efficacy sedang, dan sebanyak 27 responden (27\%) memiliki self efficacy tinggi. Sedangkan untuk kepatuhan berobata sebanyak $3(3 \%)$ responden memiliki kepatuhan berobat tinggi, $21(21 \%)$ responden memiliki kepatuhan berobat sedang, dan $76(76 \%)$ responden memiliki kepatuhan berobat rendah. Berdasarkan uji hubungan spearman rank didapatkan nilai signifikan Sig. (2-tailed) adalah 0,155 , dimana hasil ini > 0,05, sehingga dapat didimpulkan bahwa $\mathrm{H} 0$ gagal ditolak yaitu tidak ada hubungan antara self efficacy dengan kepatuhan pengobatan hipertensi lansia di Puskesmas Bareng Kota Malang.

\section{DAFTAR PUSTAKA}

Armilawaty. 2007. Hipertensi dan Faktor Resiko Dalam Kajian Epidemiologi. Bagian Epidemiologi FKM UNHAS http//ridwanamiruddin.com/2007/12/08 hipertensi-dan-faktor-risikonya-dalamkajian-epidemiologi/, (online) diakses tanggal 12 Oktober 2012

Cipolle, R.J, Strand, L.M. \& Morley, P.C., 1998, Pharmaceutical Care Practice, hal : 75, 82-83, 96-101, 116, Mc Graw Hill Company, New York

Prodjosudjadi, w. (2000). Hipertensi : Mekanisme Dan Penatalaksanaannya. Majalah Berkala Neurosains Volume 1 No 3

Riset Kesehatan Dasar(Riskesdas). (2013). Badan Penelitian dan Pengembangan Kesehatan Kementerian RI tahun 2013.Diakses: 19 Oktober 2014, dari http://www.depkes.go.id/resources/downl oad/general/Hasil\%20Riskesdas\%20 2013.pdf.
Sarafino, E. P., \& Smith, T. W. (2011). Health psychology : Biopsychosocial interactions (7th ed.). United States of America : John Willey \& Sons Inc.

Zelinski, E. M., \& Gilewski, M. J. (2004). A 10item Rasch Modeled Memory Selfefficacy Scale. Aging \& Mental Health, 8(4), 293-306. 